\title{
Correction to: Diversity and evolution of secretory structures in Sapindales
}

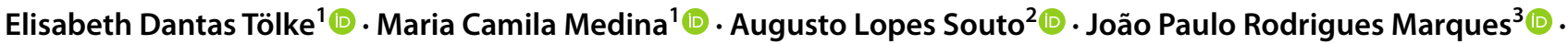

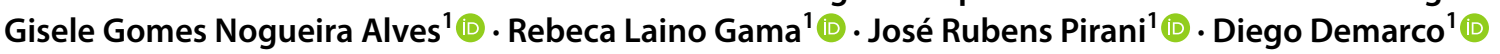

Published online: 8 February 2022

(c) The Author(s), under exclusive licence to Botanical Society of Sao Paulo 2022

\section{Correction to: Brazilian Journal of Botany https://doi.org/10.1007/s40415-021-00778-w}

In this article the reference Turner et al. (1998) was incorrect. The correct reference is:

Turner GW, Berry AM, Gifford EM (1998) Schizogenous secretory cavities of Citrus limon (L.) Burm. F. and a reevaluation of the lysigenous gland concept. Int J Plant Sci 159:75-88.

The original article has been updated.

Publisher's Note Springer Nature remains neutral with regard to jurisdictional claims in published maps and institutional affiliations.

The original article can be found online at https://doi.org/10.1007/ s40415-021-00778-w.

Elisabeth Dantas Tölke elisabeth.tolke@gmail.com

$\triangle$ Diego Demarco diegodemarco@usp.br

1 Departamento de Botânica, Instituto de Biociências, Universidade de São Paulo, São Paulo, SP 05508-090, Brazil

2 Departamento de Ciências Farmacêuticas, Centro de Ciências da Saúde, Universidade Federal da Paraíba, João Pessoa, PB 58051-900, Brazil

3 Departamento de Ciências Básicas, Faculdade de Zootecnia e Engenharia de Alimentos, Universidade de São Paulo, Pirassununga, São Paulo, Brazil 